\title{
A Philosophical Survey Of The Influence Of The Mdeia On Violence Among Youths
}

\author{
Ephraim Ahamefula Ikegbu, Esq, PhD \\ Bisong, Peter Bisong, PhD, MBA \\ Enyimba Maduka, PhD \\ Department of Philosophy, University of Calabar, Nigeria
}

doi: 10.19044/esj.2016.v12n14p351 URL:http://dx.doi.org/10.19044/esj.2016.v12n14p351

\begin{abstract}
The media are like a two-edged sword; it could built, it could also destroy. It has the capacity to increase the virtue level of a society; it also has an equal capacity to increase the vices of the society. From surveys it appears to these writers that, the media at present is wielding its vicious powers more. An increase in cases of homicides, terrorism, crime, violence and other social ills in the world is a clear testimony to this assertion. Since the state or the government exists to produce virtues in the citizens, it is imperative that the government takes serious steps to curb the dysfunctional effects of the media on the citizens and the society at large. The government should not be left alone to do this, the religious leaders, physicians, psychologists, philosophers, parents and the media practitioners themselves need to contribute their quota to evolve a media of our dreams - a media that would yield positive and beneficial fruits to the society. The media should be an instrument aimed at shaping the lives of the youth and the society. As an educative, instructive, didactic and healing therapeutic facility, the negatives associated with the media should be avoided by aspiring to embrace the positive effects of their relevance.
\end{abstract}

Keywords: Media, influence, violence, youth

\section{Introduction}

The media - whether print, electronic, visual and any other aspect constitutes a wide range of influences on the lives of people and particularly the teeming youths of the mass population. This is seen as a veritable channel through which information are broadcast out to the audience, which could have the tendency to build, mould, heal and or destroy a nascent state or an already established institution. The relevance of the media to the society cannot be overemphasized. It raises consciousness of the 
environment in the minds of people and makes them react to it according to the information that is given by the media. This is why the common saying that, information is power and he who has it rules the world remains true. The media by disseminating information could be said to be empowering people to take charge of their environment. It has the power to influence positively and also negatively. It could destroy and also could rebuild. Many people are now very much aware of this fact, for even the politicians these days know that he who controls the media is one who controls the minds of the people. Gone were the days, where people seek to control the army to be powerful or remain powerful, now people seek to control the media to win elections and stay in power.

The media therefore is very essential to the development of any society. It is regrettably also a tool that could usher in negativities to the society. There are in abundance, evidences that show and fully demonstrate that most of the unwholesome attitudes and behaviours displayed in the world today by youngsters are influenced by the media. Several acts of killings, kidnappings, prostitution, rape and other social vices and crimes against humanity are acts that were copied from the electronic and visual media. These negative impacts of the media impinge on the trust and confidence that humanity had placed on it over the ages.

This paper advocates for a moral re-engineering and re-orientation of the media for the reduction, if not total elimination of violence that is associated with the use of the media. This paper calls for a complementary effort of the physicians, media practitioners, religious leaders, psychologists, parents and the government to the tackling of the problems associated with the media. This problem is hydra-headed and is arguably beyond the hold of a single sector. All stakeholders need to join hands to fashion a better course for the media with the view of increasing its positive effect and reducing its negative effects on the society. Again, the youths are special breeds of the society who are expected or are unarguably termed as leaders of tomorrow, therefore, the media for them should be instrument of transformation, reorientation, reexamination and recreation. This paper therefore centres its logic on the necessity of ensuring a friendly media industry that is morally based for a proper, better and safer society for humans.

\section{The Mass Media: A Brief Overview}

Mass media refers to a wide array of media technologies positioned with the objective of reaching a large audience by mass communication. These technologies include broadcast media (radio, television, cinema, video films, recorded music), print media (newspaper, book, pamphlet), outdoor media (flying billboards, blimps, sky writing), digital media (internet, intranet, mobile mass communication) (Manner http://buzzle.com). Cohen 
and Kennedy (2007:339) have offered a somewhat comprehensive definition of media when they posited thus:

The media are agencies and organization that specialize in the communication of ideas, information and images of our environment, our communities and ourselves. The media also project images about 'others' and their communities

Though the history of mass media could be traced to those days when drama were performed in various ancient cultures, the phrase the media began to be used in the 1920s (Briggs \& Burke 2010). At this time the notion of mass media was restricted to only the print media. The first recorded printed book is entitled, the 'Diamond Sutra' and was printed in China in 868A.D. Johannes Gutenberg's invention of the printing press aided the production of books in large quantity all over the world, giving birth to the term 'mass media'. Today information is easily being disseminated and accessed through the radio, television, video and the internet, leading to speculations that the print media is on its way to extinction.

The media in all its forms are sensitive instrument which have the capacity of influencing the society. Media propaganda have the capacity of fuelling an already confused situation thereby propelling people into action either in the negative or in the positive direction. The media also have the capacity to overhaul the values of the people. It has the capacity to whittle down the power of an army general by exposing his plan of action. The media as a veritable instrument of leadership are both coercive and cohesive. The media can build and can also destroy. Media work significantly in the psychology, emotions and sensibility of beings, that is why censorship and proper guardianship are necessary for both practitioners and end-users of media products.

\section{The Media: It's Influence on the mind}

Media presentations influence our behaviours, sometimes unconsciously. Plato (1987) was well aware of this and thereby advised that the books to be read by children should be appropriately censored to avoid negative influence on the minds of the children. An experiment narrated by Bandara confirms Plato fears as regards the possibility of the media influencing children behaviours. The study exposed two groups of children to a play that was about picking the toys they were unfamiliar with. One of such toys is named Bobo. In one setting, an adult was made under the watch of the children to play silently with certain toys ignoring Bobo. In another setting, an adult performed a series of violent acts on Bobo. These acts include: punching Bobo on the nose, kicking it into the air, sitting on its head, slapping it while uttering aggressive words and phrases like punch him on the nose, scatter his head, kill him etc. Observers were made to score the 
children on aggression, when left alone to play with the toys. Those exposed to the aggressive adult, imitated many of the adult moves, and those exposed to the nonaggressive adult imitated his acts (Igwe 2009). This shows the correlation between the media and the behaviours of the viewers.

A study carried out in the University of Otago also established a relationship between childhood and adolescent exposure to television and violent and anti-social behaviors in young adults. The study was carried out on 1000 children born in the early 1970s from when they were the age of five to fifteen, and then followed up when they were 26 years old. The study also stipulates that "the risk of having a criminal conviction by early adulthood increase by about 30\% with every hour that children spent watching television on an average wee night"

According to Luke (1988) the level of influence is depended on the amount of time spent watching the television. With prolonged watching, the world on television becomes the real word to the children. According to Nwankwor (2009), most radio and television programs give false promise of an easy existence. Children who watch them too much lose touch of reality and existence in their practical lives. This has encouraged the proliferation of copy-cats, imitators, pirates and plagiarists. Originality and creativity that were hitherto the hallmark of youthful exuberance are gradually being eroded in our generation due to the towering influence of the media. This phenomenon has also gradually crippled the educational system. Students often write in short hands and symbols, which are direct consequences of constant emailing, internet usage, text messaging, and other social media. The students and youths are arguably careless when relating to official and unofficial engagement. Media have left the all-important role of educating, enlightening, conscientising and moralizing the moral fabric of the youth to other negative issues, which evidently generate pollution in the system. Cases of rape, harassment, armed banditry, kidnapping, internet scam and other vices, could be attributed to media consequences.

\section{The Media: Positive Influence}

The media exposes the children to a wide array of cultural and ethnic backgrounds of different people of the world, thereby enabling them to overcome cultural and family stereotypes. Most cultures have placed stereotypes on other cultures and ethnic groups. For instance, the Boki people of Cross River State in Nigeria see the Ibibios as very wicked and would not want their children to marry from them. They see the Igbos as ritualistic, the Efiks as lazy, the Yorubas as dirty. Children normally imbibe these stereotypes unless corrected by the media and other forms of education.

The media expose people to other people's views, cultures and experiences. This encourages the appreciation of not only one' culture, 
beliefs and ideas but also that of others. It develops broadmindedness in children, leading to the formation of values like tolerance, unity, peace and fellow-feeling in children. The media also deepens social confidence, increase the desire for social support and heightened media literacy in children and viewers. By exposing viewers to the knowledge of other peoples habits and ways of life, the media help diversify children's social skills, and thereby enabling them to navigate better through this technology driven society.

The news, films and documentations presented by the media that centres on social issues, help increase social awareness in children and develop their concern towards the society. Newspapers especially, update readers with the latest news and information; they also help to enhance their vocabulary; develops reading habits in children and help in improving spelling and writing skills. In fact, newspapers, magazines and newsletters are both informative and reformative.

Some media programs could help stimulate good habits like visits to the libraries, zoos, museums, bookshops, recreational settings etc. It exposes viewers to a wide arrays of features, thereby helping to broaden horizons, visions, reasoning, and inspire, educare, inform, entertain, publicize, socialize, communicate and liberate people from narrow mindedness.

In the light of the possible benefits of the media, it could be said that a child's early exposure to media is advantageous. It will help the child to carefully and clearly acquaint himself or herself with other systems of learning. This early exposure of the child to the media draws a demarcation between an urban child and a rural child. The presence of social amenities and other necessary facilities in most urban areas make it possible for a city child to adapt very effectively and also become current with issues happening around the city and beyond. For the rural child, his/her limited intellectual horizon is built around the farm and other things within the community and does not go beyond the immediate environment. The rural child therefore is often deprived of the learning benefits accorded by the media. His intellectual quotient and capabilities are grossly impaired by the things seen around his environment. There is no gainsaying the fact that environment is a dominant factor in the making and outright determination of brilliance in a being. Urban media exposure and early adaptation by a child, stimulates an epistemic consciousness of wanting to know and interpreting reality within his defined environment. This same epistemic consciousness and warrant may arguably be lacking in the rural child who seldom has access to media, whether print or electronic. 


\section{The Media: Negative Influence}

In spite of the above advantages of the media, it is sad to note that it carries in its belle very offensive and dangerous venom that could dissolve the cherished values of the society. Many believe the media is no longer to be celebrated because it has exposed the society and humans to the world of corrupt, immoral and irresponsible behaviours. The education that ought to be acquired from the media has turned to a source of pain. It is imperative to note the argument of Ikegbu (2008) that

That without being equivocal, women have been marginalized and constantly denied their place in the society. Marginalization, exploitation, subjugation, oppression and other acts of deprivation are constantly being condemned as satanic and should be avoided ... sex discrimination, inequality and other forms of marginalization on women should be condemned.

Elsewhere, Ikegbu (2012) being pained by the effect of oppression attempts to rationalize it by arguing that marginalization of beings could come from either of the sexes and this he termed as "cologenderism”. For him,

The idea of "cologenderism" is informed by the fact that the apostles of oppression, subjugation, sexual abuse, harassment, sexual starvation, exploitation and other forms of discrimination and deprivation are not externally interconnected but intraconnected. In the sense that, gender progenitor are within the same enclave.

The role of the media in the aforesaid would be to enlighten the people on the dangers of embarking on such mission of deprivation, starvation, marginalization and sexual abuse. The media should not sentimentalize the already confused scenario.

The average child is said to watch about 12000 violent acts on television annually, including many depictions of murder and rape. According to Cornstock and Straburger (1990), this exposure to heavy doses of violence in television increases violent and aggressive behaviours. Johnson (1985) corroborates this when he asserts that there is a relationship between watching violent television programs and an increase in violent behaviours in children. The categories of children believed to be more vulnerable to media violence include:

1. Children from minority and immigrant groups

2. Children from distressed families

3. Children abused by parents

4. Children who are emotionally disturbed

5. Children with learning disabilities (Josephson 1995). 
The increase in violence, cultic activities, man's inhumanity to man and other sorts of social vices prevalent in the society today are traceable to a remote or overt influence of the media. The media for instance would glorify and glamorize alcohol and drugs, making them look as if there are meant for real men. This encourages young adults to indulge in these to be like the macho men shown on TV. The after effect is always an increase in violence. Music videos also play a significant role in luring children to violence and making them more prone to premarital sex (American Academy of Pediatrics 1996). About $75 \%$ of these videos contain sexual explicit and more than half contains violence that is mostly committed against women. This gives the children the feeling that women are to be exploited. The glorification of drugs, alcohol, risky sexual and violent behaviours in the media make it hard for teens to make good and responsible decisions. Their decisions are arguably tailored towards the satisfaction of desire and passion. The media has become so strong that it has become very difficult for parents to protect their wards from its dangerous effects. Ojong (2009) expresses this in these words:

Irrespective of the efforts of the Christian parents and nonChristian parents to cage their wards, that ordinary text messages will beat all the security networks and apparatus of these parent and guardians and hit the rooms of these children without the least suspicion by the conscious and determined parents who may be jubilating to have provided enough care for their children.

The media has made it very difficult to control information. Privacy and secrets are hard to keep these days. The digital media has made this worse. The attack on the World Trade Centre in the United States of America, on September11, 2011 is a pointer to the powerful and dangerous impact of the media. Also, the war at Darfur, Serbia, Afghanistan, Liberia, Zimbabwe, Georgia etc in one way or the other have media influences on them. These wars may be regarded as mere political and societal upheavals, but when looked at critically it will be evident the contribution of the media to them. This is because the media are always ready with the aid of propaganda, to either end the violence or fuel it. On this Bok (1999) argues:

Public concern about a possible link between media violence and societal violence has further intensified in the past decade, as violent crime reached a peak in the early 1990s, yet has shown no sign of downturn; even after crime rates began dropping in 1992. Media coverage of violence, far from declining, has escalated since then, devoting ever more attention to celebrity and homicides and copycat crimes. The later, explicitly modelled on violence or films and sometimes 
carried out with meticulous fidelity to detail, are never more relentlessly covered in the media than when they are committed by children and adolescents.

It cannot be denied that media practitioners inject sentimental and emotional outlay to the practice to the extent that misinterpreting, misunderstanding and wrong analysis of what is watched, broadcasted, read and listened to could generate into a serious religios, ethnic and racial problewms to the society. Cohen and Kennedy (2007) buttressed the position above, when they argued:

A more serious example occurred in late January 2006, when a Danish newspaper published a series of cartoons, one depicting Mohammed with a turban twested into a bomb. After the cartoons were produced in a number of European countries, many in the Muslim world were outraged. Government policy towards Muslims, the newspapers' rifht to free expression and western public opinion were hopelessly conflated in the minds of many Muslims who were aghast at the newspapers' insensitivity and ignorance (images of the prophet are forbidden) and at the West's attacks on Islam. Riots and protests in Indonesia, Gaza and elsewhere immediately followed.

From the above, it is evident that media at any given time can trigger off violence due to what message the audience receive and the impact such message made in their psychology of understanding. Indeed, sometimes in 1993 and 1994 in the state of Nigeria, the media broadcast would have resulted to the collapse and disintegration of the country. The annulment of the June 12, 1993 presidential election alleged to have been won by chief Mooshod Abiola of the Social Democratic Party over chief Tofa, of the National Republican Convention triggered off ethnic rivalry in the country Nigeria. Also, the self-declaration as president by Chief Abiola in 1994 brought series of problems due to the broadcasting strategy adopted by the media practitioners. The government controlled media houses and the private-owned media houses were engaged in ideological and strategic war of broadcasting. The government-controlled was coming from the angle of being on top of the situation, the private controlled were rather giving a contradictory information on the preparedness of foreign soldiers or international military aid on the side of Abiola.

Consequently, the improper media handling of the situation caused the loss of many lives and properties. This ugly phenomenon is not peculiar to Nigeria, for countries such as Syria, Gaza, Sudan, Liberia, Pakistan etc have at one time or the other experienced media mishandling of information which have resulted to monumental violence. 
There are strong indications therefore, that most of societal crimes and crises today are traceable one way or the other to the media mismanagement of information. Most acts of homicides and other criminalities perpetrated by infants and even adults are traceable to unguarded exposure to the television and other electronic gadgets at home and public places. It has therefore, become imperative that actions should be taken to reposition the media to yield better dividends to the society.

\section{Repositioning the Media: An Urgent Necessity}

Chris Ijiomah (1996) in his work "Humanising Epistemology" is of the view that authentic education and wisdom is that which is geared towards solving human problems. For him, knowledge should serve no other purpose than to solve problems that confront humanity. If knowledge serves negative purposes, it is not wisdom. It is in line with the above premise that the manufacture of ballistic missiles, nuclear weapons, war machines and weapons of mass destruction are condemned. In likewise, media education becomes condemnable, if it serves dysfunctional effects. Media ought to be a tool for the promotion of virtuous acts but on the contrary it has become an avenue and training ground for the promotion of social vices like prostitution, violence, gay relationship, child trafficking, gangsterism, cultism, examination malpractice, election rigging and other unpleasant acts.

We believe that a concerted effort need to be put together to save the society from the disastrous effects of the media. The government, physicians, psychologists, moral philosophers, religious leaders as well as parents and other concern bodies need to play their part to ensure that the dangers emanating from the media could be averted.

The city or state as held by Aristotle (1958) "exist not only for the sake of living but rather, primarily for the sake of living well. For him the state or more properly government exist to produce virtues in people, so as they can live meaningfully lives in the society. Since the media as we have already stated could contribute meaningfully to the formation and molding of good character, it becomes necessary for the government to help purge the media of negative influences, so it could positively affect the citizen. This paper is very mindful and of full acknowledgement of Socrates dicta that 'unexamined life is not worth living' and 'man know thyself'. The implication of these two morally cloned dicta by a moral pillar are to the effect that peoples conduct should stand them out and so, whatever media education one is to acquire should be one aimed at ensuring a complementary unity and not one that could segregate the entire community by way of violence, kidnapping, sexual rape and adoption. Government should enact special laws which subject editors to arrest and punishment. Media reporters, presenters, writers etc who are found guilty of false 
presentation, defamatory reports, false allegation and other such vices should be made to face the law. Also pornographic movies or magazines, books, cable station, websites as well as seductive and violent centred movies need to be proscribed or presented at period when the children should be sleeping. Also information from the media should be properly censored by the government along these lines:

1. News items, programs information, advertisement etc which the child are exposed to, should be carefully selected and censored.

2. The items and program for visual and audio consumption should be properly scheduled in consideration of the child. The programs that are likely to corrupt the minds of the child should be broadcasted at hours when the child will be asleep.

3. The age boundaries for listening or watching radio and TV programs respectively should be properly delineated and enforced through proper time management of programs.

4. Religious, moral and educationally inclined programs should be presented more, especially at hours when the children would be awake.

5. The internet should be censored to ensure that pornographic materials are removed.

The job of safeguarding children from media influence should not be left for the government alone; other stakeholders too need to get involved. The religious leaders need to concentrate more on the teachings of morality would enthrone virtues not only the media practitioners but also to the children, so that they consciously would avoid media programs that are immoral. It is however lamentable that these days the churches and other religious bodies now see the teachings on morality as outdated. It is prosperity and miracle messages they preach. Some even preach that righteousness does not take one to heaven but a mere belief in Jesus Christ. Teachings like this will only help to dampen the desire for virtue.

The physicians too need to do their part by discussing with parents as regards their children's exposure to media and provide guidelines on ageappropriate use of all forms of media. Parents too need to play their part by guiding their children appropriately on media usage. According to Cole (1997) parents play a special role in their children's social learning through the media. The moral philosophers also need to add their quota to this effort to rebrand the media. They as the think-tank of the nation need to bring out the best ways to bring more positive effects from the media.

\section{Conclusion}

Plato, one of the foremost moral philosophers that lived after Socrates was so pained by the degrading state of the minds of the Athenians and the need to extrapolate corruption from all segments of existence. Been 
dissatisfied with the leaders and their corrupt behavious, he felt that the cause of these leadership failures are traceable to ignorance, hence the need to banish ignorance. Plato also, considered the fragile nature of the minds of mirrors in Athens and he reasoned that proper censorship of books to be exposed to the Athenian children be carried out. This is to make sure that children of high moral standard are created for the Athens. He specifically warned that books written by Homer and Hesiod should not be read by them. The said books presented the gods involving in immoral acts. The necessity of the consciousness of moral upbringing has been of ages. This paper aligns itself with the submission of Ikegbu and Ogar when they argue that "rebranding implies refusing to do with one's conscience" (101-102). In this case, the paper submits that rebranding of the media and the minds of the youths would take away the seeming negativity associated with media and equally overhaul the mental element of beings so as to grab only those ingredients of peace, stability, even development and complementary unity.

\section{References:}

American Academy of Pediatrics, Committee on Communication impact of Music Lyrics and Music Videos on Children and Youth. Pediatrics, 1996, 98: 1219-1221.

Bok, S. (1999). Philosophy and Education in the Third Millennium. Eds. G.O. Ozumba, O.I. Obinna, I.J.Nwankwor, Nkpor: Verax Global.

Briggs, A. \& Burke, P. (2010). Social History of the Media from Gutenberg to the Internet. Polity Press.

Cohen, Robin \& Paul Kennedy (2007). Global Sociology. Second edition. UK: Palgrave Macmillan.

Cole, R. (1997). The Moral Intelligence of Children. New York: Random House.

Cornstock, G. \& Strasburger, V. (1990). Deceptive Appearance: Television Violence and aggressive Behaviour. J. Adolesec Health Care, Vol.11, pgs 31-44.

Igwe, D. (2009). "Ethical consideration of Mass Media Education”. Philosophy and Education in the Third Millenium. Eds. G.O.Ozumba, Q.I. Obinna, I.J. Nwankwor. Nkpor: Verax Global.

Ijiomah, C. (1996). Humanizing Epistemology. Owerri: AP Publication.

Ikegbu, Ephraim and Joseph Ogar (2009). "The Synergy of Philosophy. Leadership and Good governance”. The Leajon: An Academic Journal of Interdisciplinary Studies. Vol.1.no.1, 97-103.

Ikegbu, Ephraim A. (2008). “women and Socio-Political Development of Nigeria”. African Pentecost: Journal of Theology, Psychology and Social Work. Vol. 2, no. 2, pp. 82-90. 
Ikegbu, Ephraim A. (2012). “The Place of Women in Political Development”. G.O. Ozumba, F.O. Eteng and M. Okom (Eds). Nigeria: Citizenship Education Second Edition. Aba: A.A.U Vitalis Books.

Johnson, W. (1985). Television Violence: A Review of the effects on Children of different Ages. Ottawa: National Clearinghouse on Family violence.

Luke, C. (1988). Television and your Child: A Guide for concerned Parents. Toronto; TV Ontario.

Manohar, Utaru. "Different Types of Mass Media”. http://buzzle.com. Retrieved October 3, 2014.

Nwankwor, I. (2009). "The Radio and the Television the Moral Eucation of a Child". Philosophy and Education in the Third Millennium. Eds. G.O.Ozumba, Q.I. Obinna, I.J. Nwankwor. Nkpor: Verax Global.

Ojong, K. (2009). Church Sermon. Jesus Sanctuary Auditorioum of Redeemed Christian Church, Calabar Province. $1^{\text {st }}$ March, 2013.

Plato (1987). The Republic. Trans. Desmond Leo. London: Penguin Books. 